\title{
Study on Gas-solid Flow Characteristic in Slag Cooler of Circulating-fluidized Bed Boiler
}

\author{
Wei Li, Yanping Liu \\ Beijing City University, The Third Street of Yangzhen, Shunyi District, Beijing, P.R.China \\ North China Electric Power University, NO.2 Beinong Street, Changping District, Beijing, P.R.China \\ liwei-625@163.com, lyp@ncepu.edu.cn
}

\begin{abstract}
Keywords: Circulating-fluidized bed boiler, slag cooler, gas-solid flow, Euler-Lagrange, numerical simulation.

Abstract: In order to test the predicting ability of numerical calculating and provide the reliable data for the successive design, this study was designed to trace the particle path in the complete fluidized flow field in the slag cooler according to the characteristic of the gas-solid flow by the Euler-Lagrange model of FLUENT software and the continuous phase and particle phase coupling algorithm. The study focused on the movements of particles in different diameter in the cooler, the interaction of the two-phase flow, the influence of the cooler internal structure on the particle track, and the velocity changing laws of the particles in every directions. The representative results was comparied with the practice. The results showed that the slag cooler had higher efficiency with unequal wind, the outflow had highest velocity at outlet when the entire flow field is uniform flow, the turbulence energy of the flow field changed obviously, the turbulence near the division wall was advantage to the particle roll over the wall, which was help for separating slags, and the slag cooler was inefficiency if the velocity of slag is too high. The model full reflected the gas-solid flow characteristic in the slag cooler.
\end{abstract}

\section{Introduction}

The burning technology of circulating-fluidized bed boiler is efficient, low polluted and low-cost. It has advantages of extensive adaptability, high burning efficiency, good condition performance, large range of load accommodation and integrated use of slag. This technology is extensively used in electric power industry. As an important part of Circulation Fluidized Bed Boiler, slag cooler's abnormality is the main reason for the pause of the machine group and the reduction of load.

At present, the problems in the slag cooler working process include plugging up of the slag cooler's inlet, coking or slagging board agglomeration in slag cooler, coking or plugging up of the outlet caused by high temperature, blocking the running part or valve of bottom slag discharge and transportation system, lacking of the emergency measure. These troubles have close relationship with the interior structure and the hydromechanical characteristic of the slag cooler. More and more people pay attention to characteristic of the gas-solid flow in the cooler with the widely use of slag cooler with water-air. In the past,peole studied the hydromechanical characteristic in slag cooler by experiments.For example, the rate of discharging slag, the fluidized wind velocity, match wind rate, the bed pressure drop and other running parameters. But this method has the following shortcomings: strong experience, narrow range, error in measure, the results depending on the condition of the experiment, costliness and so on. So it will waste time and money if the research only depends on experiments.

Imitating of the gas-solid hydromechanical characteristic in the slag cooler by FLUENT software and the dynamic numerical method provided an effective tool to design and study the slag cooler.

\section{Numerical Models}

According to the current situation, we chose slag cooler with water-air as investigative object. Its structure is shown in Fig.1. It has the advantages of extensive adaptability, low fluidized wind velocity and litter abrasion. But it is strict with the diameter of slag ${ }^{[1]}$. According to the characteristic 
of the gas-solid flow in the slag cooler, this study was designed to trace the particle path in the complete fluidized flow field in the slag cooler by the Euler-Lagrange model of FLUENT software and the continuous phase and particle phase coupling algorithm. The interaction between the movement of particles in different diameters and the two-phase flow in the cooler and the velocity changing laws of the particles in every directions were studied ${ }^{[2 \sim 4]}$.

The simulation adopted the Euler-Lagrange model provided by FLUENT software. The basic thinking is that integrated to the differential equation that all kinds of variate conservation relations of the gas phase in Euler coordinate system according to the unit control volume. All of these were made up of the difference equation, including the fountain phase interacted between phases. For particle group, their dimension group and the movement of all kinds of original places or directions in Lagrange coordinate system were considered. We integrated them in the unit of the gas phase and tried to find the track of the particle and the change history of the particle's velocity, temperature and dimension (or

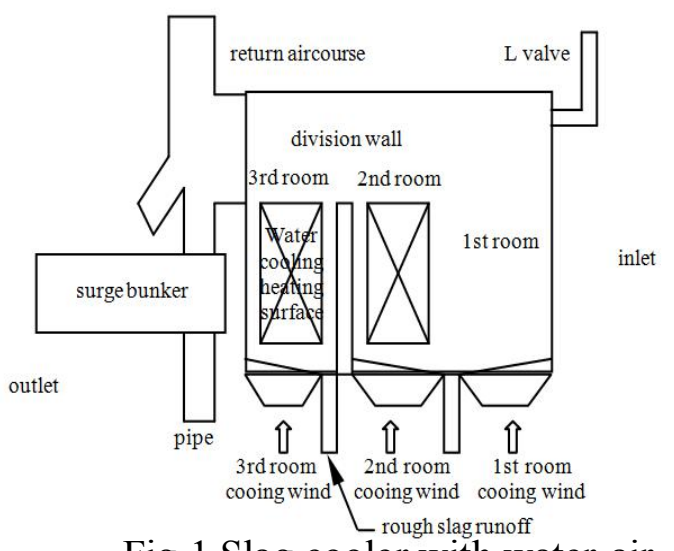

Fig.1 Slag cooler with water-air density). Phase change of the particle and the resistance to the air result in the momentum fountain, we applied it to the velocity and concentration field of the gas phase. On the other hand, the gas phase field affected the track of the particle and the change of track. This paper mainly discussed the movement in constant temperature and ignored the transfer of heat and mass.

\section{Governing Equations of Gas Phase}

Adopting the Euler method to simulate the gas phase, the governing equation in the rectangular coordinate system was:

Continuously equation:

$$
\frac{\partial}{\partial x_{i}}\left(\rho u_{i}\right)=0
$$

Momentum equations:

$$
\begin{aligned}
& \frac{\partial}{\partial t}\left(\rho u_{i}\right)+\frac{\partial}{\partial x_{j}}\left(\rho u_{i} u_{j}\right)=\frac{\partial}{\partial x_{j}}\left[\mu\left(\frac{\partial u_{i}}{\partial x_{j}}+\frac{\partial u_{j}}{\partial x_{i}}\right)-\left(\frac{2}{3} \mu \frac{\partial p}{\partial x_{i}}\right)\right] \\
& -\frac{\partial p}{\partial x_{i}}+\rho g_{i}+F_{i}-\frac{\partial}{\partial x_{i}}\left(\rho u_{i}^{\prime} u_{j}^{\prime}\right)
\end{aligned}
$$

The kinetic energy k equation of turbulent flow:

$$
\frac{\partial \rho k}{\partial t}+\frac{\partial}{\partial x_{j}}\left(\rho u_{j} k\right)=\frac{\partial}{\partial x_{j}} \frac{\mu_{i}}{\sigma_{k}} \frac{\partial k}{\partial x_{j}}+G_{k}-\rho \varepsilon
$$

$\varepsilon$ equation: :

$$
\frac{\partial}{\partial t}(\rho \varepsilon)+\frac{\partial}{\partial x_{j}}\left(\rho u_{j} \varepsilon\right)=\frac{\partial}{\partial x_{j}} \frac{\mu_{i}}{\sigma_{\varepsilon}} \frac{\partial \varepsilon}{\partial x_{j}}+C_{1 \varepsilon} \frac{\varepsilon}{k} G_{k}-C_{2 \varepsilon} \rho \frac{\varepsilon^{2}}{k}
$$

There are 5 experiential constants in the equations, as shown in Table 1: Table 1 Experience constants

\begin{tabular}{ccccc}
\hline $\mathrm{G}_{k}$ & $\mathrm{C}_{1 \varepsilon}$ & $C_{2 \varepsilon}$ & $\sigma_{k}$ & $\sigma_{\varepsilon}$ \\
\hline 0.09 & 1.44 & 1.92 & 1.0 & 1.3 \\
\hline
\end{tabular}

\section{The Governing Equation of Particle Phase}

When building the model of particle phase, the interaction between the particles was not be considered. The gravity acted on the particles was taken into account. The gas drag force acing on the particles was disassembled into time-mean field and rippled field. From these we could get the governing equations of particle phase under two-phase flow condition in constant temperature:

$$
\frac{d u_{p}}{d t}=F_{D}\left(u-u_{p}\right)+g\left(\rho_{p}-\rho\right) / \rho_{p}+F_{x}
$$




$$
F_{D}=\frac{18 \mu}{\rho_{p} D_{p}^{2}} \frac{C_{D} \operatorname{Re}_{p}}{24}
$$

$\mathrm{U}$ is the fluid phase's velocity, $\mathrm{u}_{\mathrm{p}}$ is the particle's velocity, $\mu$ is the fluid's dynamic viscosity, $\rho$ is the fluid's density, $\rho_{p}$ is the particle's density (skeleton's density), $D_{p}$ is the particle's diameter, and $\operatorname{Re}_{p}$ is relative Reynolds number (particle Reynolds number), its definition is:

$$
\begin{gathered}
\operatorname{Re}_{p}=\frac{\rho D_{p}\left|u_{p}-u\right|}{\mu} \\
C_{D}=\alpha_{1}+\frac{\alpha_{2}}{\operatorname{Re}}+\frac{\alpha_{3}}{\operatorname{Re}^{2}}
\end{gathered}
$$

For global particles, within the certain range of the Reynolds number, $\alpha_{1}, \alpha_{2}, \alpha_{3}$ in previous equations are constants ${ }^{[5]}$.

In this paper, we adopt the trace method of turbulent flow particle group to pursue the track of the particle, and calculate the diffusion velocity of the particle that enclose the mean orbit of the particle group using stochastic method. The relevant concentration of particle is shown by Gauss Probability Density Function (PDF).The diffusion of the particle caused by turbulent flow pulse determines the PDF's variance. To get the ensemble average of the of particles' movement ( this average will replace the particles' movement ), we will gain the particle group's equation about the ensemble average. Then we will get the mean orbit of the particle group by solving this equation.

The movement track of the particle in space is:

$$
\frac{d x}{d t}=u_{p}
$$

\section{Calculation and Results}

\section{Grid Partition}

When calculating the geometrical dimension, we had to refer to the trim size of the slag cooler, taking $220 \mathrm{t} / \mathrm{h}$ circulating-fluidized bed's wind water combined slag cooler in some electric power plant as the physical model. The slag cooler's length was $4086 \mathrm{~mm}$, width was $1380 \mathrm{~mm}$ and area was $5.638 \mathrm{~m}^{2}$. Its main design and movement parameters concluded:

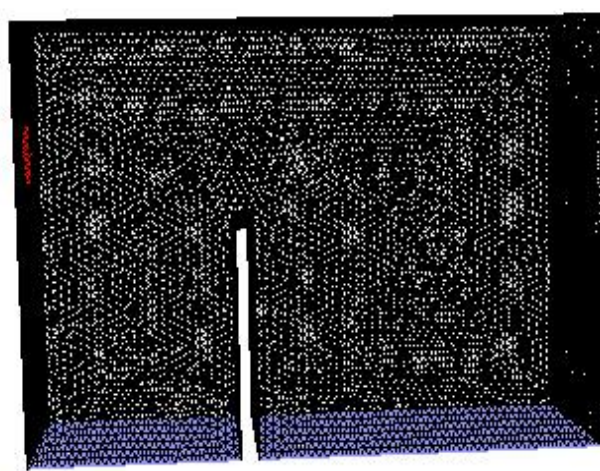

Fig.2 Grid partition rated quantity of lash flow is $4.02 \mathrm{t} / \mathrm{h}$, and the fluidized wind velocity is $3.0 \mathrm{~kg} / \mathrm{s}$. The grids were not structural. We divided the three-dimensional model by adopting tetrahedral structure. The rapid change draw on unit volume would cause big truncation error, so we smoothed the grids. In order to reach the request of the calculational precision, we divided enough grids. The sum of the grids was 516694, as shown in Fig.2.

The bottom slag that circulating-fluidized bed discharged was wide sieving matter. In this paper, we calculated the particle phase according to the bottom slag's characteristic of the practical electric power plant. According to the cold-state experiment, we got the bottom slag's mean density is $1400 \mathrm{~kg} / \mathrm{m}^{3}$, and its mean diameter is $3 \mathrm{~mm}$, the particle's distributing law as shown in Table 2 .

Table 2 The distribution of solid particle diameter

\begin{tabular}{cllll}
\hline $\begin{array}{c}\text { Diameter(m } \\
\mathrm{m})\end{array}$ & $1-3$ & $3-5$ & $5-8$ & $>8$ \\
\hline Weight & 49.9 & 16.5 & 22.7 & 10.82 \\
percent $\%$ & 2 & 4 & 2 & \\
\hline
\end{tabular}

\section{Analysis and Comparison of the Calculatingly Results}

\section{Continuous phase flow field}

We got the boundary condition of inlet according to the experimental measured value by adopting the boundary condition of the velocity inlet ${ }^{[6]}$. The boundary condition of pressure outlet was set so as not to reflux. It was low speed fluidized state in slag cooler. The critical fluidized wind speed was generally at the range of $0.65-0.9 \mathrm{~m} / \mathrm{s}$. That was to say, when the velocity of air space section reaches $0.9 \mathrm{~m} / \mathrm{s}$, the 
slag completely becomed fluidized state ${ }^{[7]}$. By adopting unequal wind for the simulation of continuous phase and taking the critical fluidized wind velocity as the inlet velocity, the particle phase was analyzed in the condition of the flow field ran well.

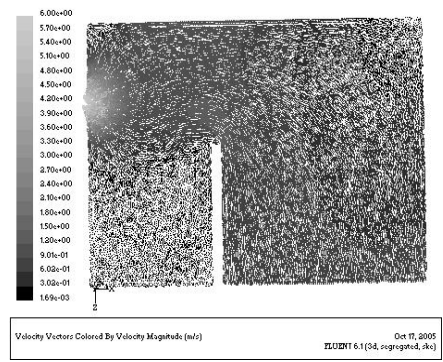

Fig.3 $(\mathrm{Y}=0)$ Velocity vector of the flow field in Y profile

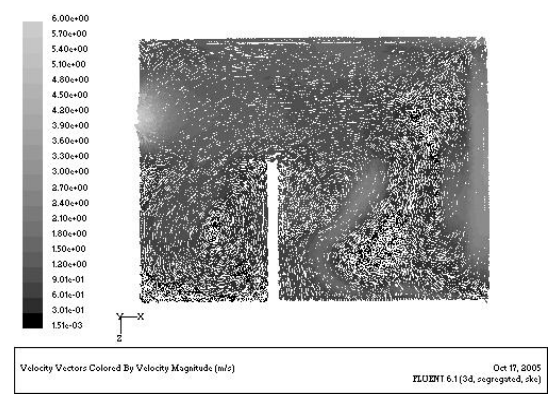

Fig. 5 Velocity vectogram of the flow field entering into $5-8 \mathrm{~mm}$ particles

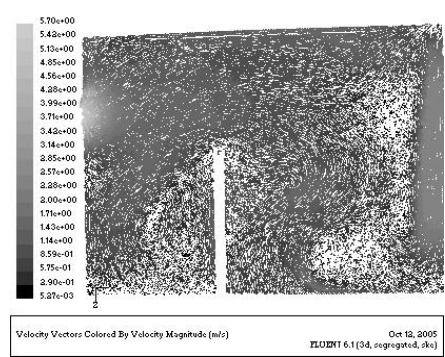

Fig.4 Velocity vectogram of the flow field entering into $0-5 \mathrm{~mm}$ particles

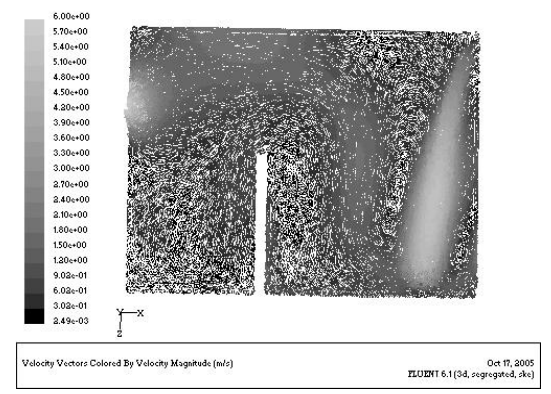

Fig. 6 Velocity vectogram of the flow field entering into $8-10 \mathrm{~mm}$ particles

Fig. 3 is the $(Y=0)$ velocity vector of the flow field in $Y$ profile. Because of adopting unequal wind (the wind velocity of 1,2 room is bigger than 3 room's), we could clearly see the disparity of the velocity from the Fig. 3a). The turbulent energy of the flow field changes evidently, and the total flow field was comparatively uniformity. Because the outlet is small, the velocity in outlet would increase rapidly and generate the maximum. From the figure we can see that the flow field in slag cooler can be divided into the inlet of slag, down eddy acceleration and outlet acceleration. These three sections will affect the particle's track. The air flow's velocity in the top right side of the slag inlet section is small. Slag enter from the top right side. Because the velocity is small, the slag free-falls through the action of gravity. After falling into the eddy acceleration section, the slag roll up by eddy and moved around the division wall. The division wall does a good cooling action. It prolong the time the slag stay in the slag cooler and make the slag cooled fully. The most slag enter the outlet acceleration section and flew off the slag cooler successfully after they round the division wall. Part of big particles have the trend to fall. The fluidized wind just accelerat them and make them not to fall. If slag has a big incident velocity when they enter the slag cooler, the slag will direct enter the level outlet acceleration section, and fly off the outlet. Because the time is too short, the slag can't be cooled fully. It may result in coking or some other problems. So the slag shouldn't have a big velocity when they enter the slag cooler.

Fig. 4 is the velocity vectogram of the flow field entering into $0-5 \mathrm{~mm}$ particles. It reflect the interaction between particle flow and flow field after particles enter into the flow field. Compared with Fig.3, we can clearly see the particles' track. The velocity of the whole flow field increased after adding the particle flow, and the velocity trends to be uniformity. There's eddy in every reverse area particles accelerating area. It make the areas of eddy increased. The movement track of particles reflects that small diameter particles can successfully get across the division wall and be normally discharged from the outlet.

Fig. 5 is the velocity vectogram of the flow field entering into $5-8 \mathrm{~mm}$ particles. It reflects that some particles fall into the third cooling room after getting across the division wall and finally can not be discharged from the outlet because of their big diameters. But this kind of particles is fully cooled in the first and second cooling room, so they will not result in the coking problem that caused by high temperature. These particles fall into the third room can become the bed material. 
Fig. 6 is the velocity vectogram of the flow field entering into $8-10 \mathrm{~mm}$ particles. From the figure we can see that only a few particles could get across the division wall and fly off the outlet. Most particles fall into the bottom after they entering the cooler because of their big diameters.

\section{Particle's relative motion velocity}

The following figures are typical single particle's velocity variation curves.

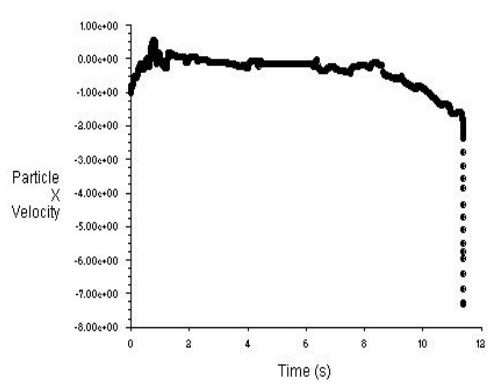

Fig.7 The velocity variation curves of the particles at $\mathrm{Z}$ direction

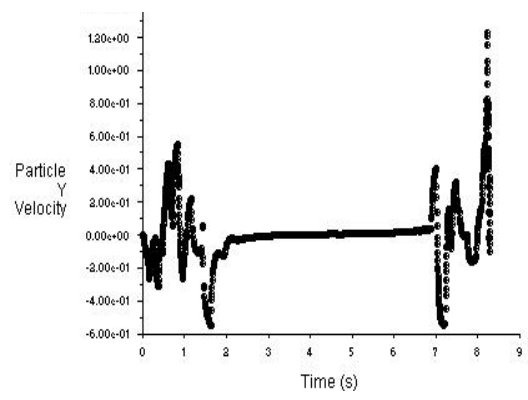

Fig.9 The velocity variation curves of the particles at $\mathrm{Y}$ direction

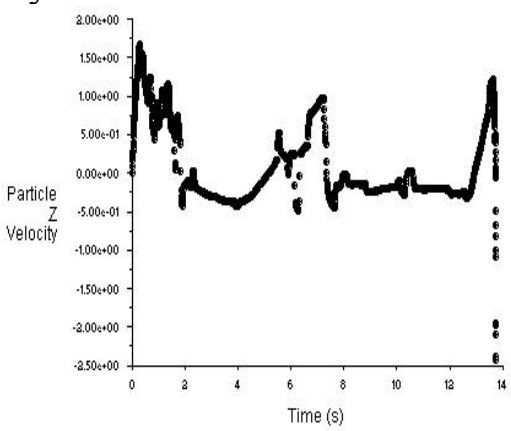

Fig. 8 The velocity variation curves of the particles at $\mathrm{X}$ direction

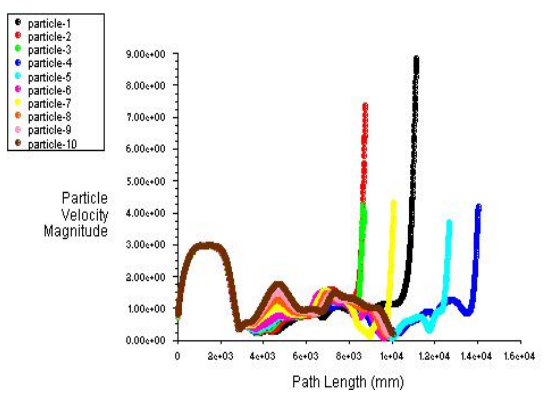

Fig.10 The velocity variation curves of particles in different diameter along orbit direction

Fig. 7 is the velocity variation curves of the particles at $\mathrm{Z}$ direction. From this figure we can see that with the movement of the time, particle's velocity sometimes increase and sometimes decrease. Its direction is also changed. All of these is the result of that particle move along with the cooling wind. As a whole, under the cooling wind, the particle's velocity is always upward and the vertical velocity is not changed too much.

Fig. 8 is the velocity variation curves of the particles at X direction. Air's transverse velocity gradient results in that the particle's velocity in two sides are different and it will make the particle rotate. From the figure we can see that the horizontal force has nothing to do with the particle. It is because that we simplify the calculational model. The particle is almost discharged in horizontal velocity of the inlet.

Fig.9 is the velocity variation curves of the particles at Y direction. The particle's movement time will be prolonged in the slag cooler if the velocity of this direction becomes bigger. From the figure we can see that the velocity at $\mathrm{Y}$ direction in inlet and outlet is comparative big, and this makes the particle's movement track become spirality, and prolongs the cooling time of the particle. In the middle of the curse, the velocity of this direction is almost zero. This will assure that the particle will not touch with the surface of the slag cooler's middle section. If the particle touch with the suface, the particle may fall into the bottom along the surface.

Fig. 10 is the velocity variation curves of particles in different diameters along orbit direction. From the figure we can see that small particle's figure of velocity is bigger than the big one's. But as a whole, the gas and solid's relative velocity are all big, especially for the big particles. The overview is that the change of velocity is complex and the total trend is rise.

\section{Conclusion}

This paper discussed the particle's typical track in the slag cooler, the influence which the cooler internal structure to the particle's track and the velocity changing laws of the particle in every 
directions by making a numerical simulation for the slag cooler with water-air of the circulating-fluidized bed adopting two-phase flow Euler model and dispersed phase model provided by the software of FLUENT. The results indicated that:

(1) If adopting unequal wind, the efficiency of slag discharging would be high.

(2) The turbulent flow of the flow field changed evidently. The whole flow field comparatively uniformity, and the velocity of the outlet was big;

(3) The eddy existed round the division wall in favor of the particle to get across the division wall. At the same time, the division wall could select the particle's diameter.

(4) The velocity that slag entering into the cooler could not be too big. Otherwise, the slag cooler could not do the cooling job well.

In addition, this kind of slag cooler was strict with the particle's diameter. According to the statistical calculation of a large number of particles with different diameters, we found that this kind of slag cooler's excretion rate was very low for the particles whose diameters are bigger than $10 \mathrm{~mm}$, the excretion rate was about $10 \%$. But for the particles whose diameters were less than $8 \mathrm{~mm}$, the excretion rate was comparatively high.

In this paper, we made a numerical simulation which was model suitable for the research of the slag cooler, and tried to research the particle's movement track and motion velocity by adopting the method of dispersed phase. It made up the shortcomings of the Euler mode, and showed a integrated simulation method and post-treatment which included the grids division of the computational domain, scattering the governing equation by adopting the method of finite volume, the enactment of the parameters and so on. The research provided a reliable basis for the optimizing design of the slag cooler's structure. Furthermore the data and the movement laws from the research provided reliable reference and operational guide for the operation of the slag cooler.

\section{References}

[1] Cen Kefa, Ni Mingjiang,Luo Zhongyang et al. Circulating-fluidized bed boiler's academic design and operation[M]. Beijing: China Electric Power publishing company:1998.127-138

[2] Bolio E J,Mostorancos E and Sinclair J L.Dilute turbulent gas-solid flow in risers with particle-particle interactio_AIChE J.[J]1995,41(6):1375-1388

[3] Lee S L and Wiesler M A.A unified theory on particle transport in a dilute tow-phase-II. Int J Multiphase Flow [J]1987,13(2):112

[4] Cai Xinchun, Ye Ning. The discussion of the fluidized bed selectivity slag cooler's operational technology [J].Boiler manufacture, 2002(1): 4-6.

[5] S.A. Morsi and A.J. Alexander. An Investigation of Particle Trajectories in Two-Phase Flow System [J].Fluid Mech., 1972, 55 (2):193-208

[6] Guo Liejin. two-phase multi-phase hydrokinetics [M]. Xi'an: Publishing company of Xi'an Traffic University, 2002.340 356

[7] Ye Xuemin, Yan Weiping, Yin Libao. The cold state pattern experiment of 450t/h CFB Boiler wind water combined selectivity slag cooler[J]. Power Engineering 2004(8):593-597.

[8] Ye Xuemin, Li Chunxi, Fan Xu. The cold state eject characteristic of the wind water cold selectivity slag cooler under unequal wind[J]. Thermal Energy Power Engineering 2005(1):73-75. 